\title{
Competencias digitales y necesidades formativas de e- estudiantes de la Universidad Autónoma de Chihuahua
}

Digital Competences and Formative Needs of University E-Students of Autonomous University of Chihuahua

Habilidades digitais e necessidades de treinamento de e-estudantes da Universidade Autônoma de Chihuahua

José Luis Bordas Beltrán

Universidad Autónoma de Chihuahua, México jbordas@uach.mx https://orcid.org/0000-0003-1465-3662

Ana María De Guadalupe Arras Vota Universidad Autónoma de Chihuahua, México aarras@uach.mx https://orcid.org/0000-0002-4115-9646

María Del Carmen Gutiérrez Diez

Universidad Autónoma de Chihuahua, México cgutierr@uach.mx https://orcid.org/0000-0001-9159-3283

Alma Lilia Sapien Aguilar Universidad Autónoma de Chihuahua, México Isapien@uach.mx https://orcid.org/0000-0001-7222-2612 


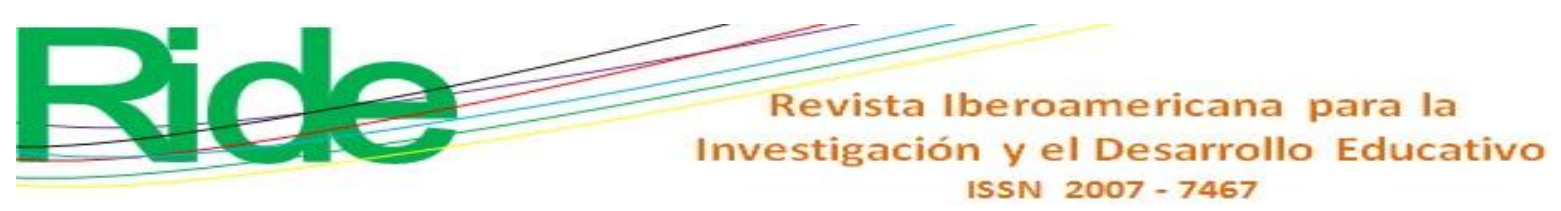

\section{Resumen}

Este artículo expone un estudio cuyo objetivo fue cotejar las percepciones de un grupo de estudiantes sobre las competencias que tienen en tecnologías de información y comunicación con las de sus docentes. Los alumnos participantes pertenecen a la licenciatura en línea de la Facultad de Contaduría y Administración de la Universidad Autónoma de Chihuahua. El instrumento de medición comprendió seis tipos de competencias: básicas, de aplicación, profundización, trabajo en equipo, aprendizaje permanente y éticas. Metodológicamente, se planteó como un estudio de caso, cuantitativo; se desarrolló por procedimientos analítico-sintético y teórico-deductivo. Entre los resultados destaca la disparidad entre las valoraciones de estudiantes y docentes, con la tendencia de los primeros a asignarse evaluaciones superiores a las asignadas por los maestros, aun en competencias complejas. La indagación muestra que los alumnos, aunque tienen competencias digitales básicas, requieren reforzar las de aplicación y profundización, que remiten al uso de bases científicas informativas, de análisis, trabajo colectivo y conciencia ética.

Palabras clave: brechas digitales, competencia, percepción, TIC.

\section{Abstract}

This article presents a study whose objective was to compare the perceptions of a group of students about the competences they have in information and communication technologies with those of their teachers. The participating students belong to the online degree from the Facultad de Contaduría y Administración of the Universidad Autónoma de Chihuahua. The measurement instrument comprised six types of competences: basic, application, deepening, teamwork, lifelong learning and ethics. Methodologically, it was proposed as a quantitative case study; it was developed by analytic-synthetic and theoretical-deductive procedures. Among the results, the disparity between the valuations of students and teachers stands out, with the tendency of the former to assign higher evaluations to those assigned by the teachers, even in complex competitions. The investigation shows that the students, although they have basic digital competences, need to reinforce those of application and deepening, which refer to the use of informative scientific bases, analysis, collective work and ethical conscience.

Keywords: digital gaps, competence, perception, ICT. 


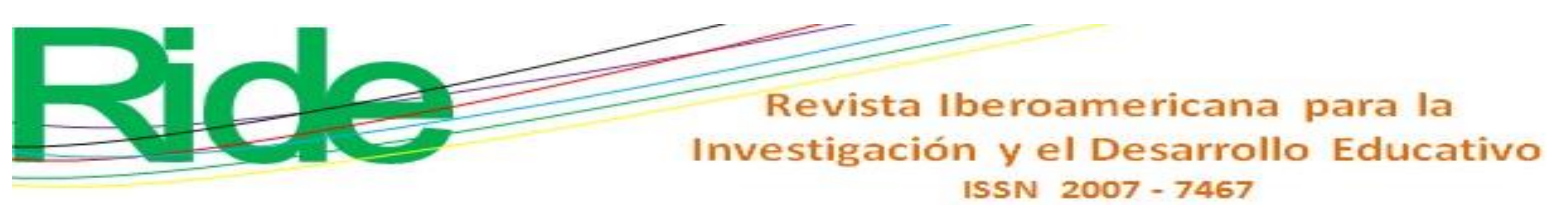

tienen uso de razón (Ling y Bertel, 2013, p. 1). Las TIC, entonces, han modificado la forma en que se constituyen las relaciones, sean estas interpersonales, intergrupales o interinstitucionales.

En el ámbito de la educación, esta ha de aprovechar todas las funciones que las TIC aportan (Mañas y Roig, 2019, p. 80), principalmente aquellas indispensables para enriquecer los procesos de enseñanza y aprendizaje, así como diversificar las formas de aprender de los estudiantes (López, Gónzalez, Aguiar y Artiles, 2017, p. 1304). Precisamente un aspecto favorecido y evidenciado por las TIC fue la pluralidad de modos para recopilar información y transmitirla; de ahí que sea una prioridad que los estudiantes adquieran y desarrollen competencias para convertir la mera información en conocimiento, y aprendan a aprender a lo largo de la vida, de manera que sean capaces de superar los retos de una realidad cambiante (Mañas y Roig, 2019, p. 80). En esa mudable realidad, existen brechas, barreras que impiden el desarrollo de competencias para las TIC. No tener dichas competencias equivale, verdaderamente, a no ser capaz de acceder a la tecnología ni a las estructuras administrativas ni a los recursos disponibles ni a un mejor rendimiento del tiempo (Sing, 2010, p. 387). El reto de las instituciones de educación superior es reducir tales brechas y propiciar el desarrollo de las competencias digitales de estudiantes y docentes.

Aquí vale puntualizar nuestra noción de competencia. Las competencias son el resultado de dirigir el conocimiento hacia una actividad práctica y definida (Llamas y Macías, 2016, p. 578) y, en tanto praxis concreta, comprende procesos factibles de desarrollar a partir de las motivaciones internas de cada individuo (Hinojosa, González y Castillo, 2017, p. 4). Hablar de competencias es referirse a las capacidades que un individuo utiliza para actuar, disponer o movilizar un conjunto de recursos cognitivos, esquemas de percepción y evaluación a fin de resolver escenarios complejos (Guzmán, Marín e Inciarte, 2014, p. 25). En el campo de las TIC, las competencias digitales se conciben así: "La capacidad de desarrollar y generar conocimiento ante las diferentes posibilidades asociadas a las tecnologías y a los distintos retos que se plantean en una sociedad donde cada día es más necesario participar de forma significativa y activa" (Llamas y Macías, 2016, p. 1).

[Dicha participación es posible] e implica el uso seguro, crítico y responsable de las tecnologías digitales para el aprendizaje, en el trabajo y para la participación en la sociedad, así como la interacción con estas, a partir de la obtención, evaluación, producción, almacenamiento, intercambio de información, 


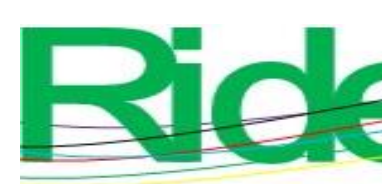

Revista Iberoamericana para la
Investigación y el Desarrollo Educativo
ISSN $2007-7467$

comunicación y participación en redes de colaboración (Consejo de la Unión Europea [CUE], 4 de junio de 2018, p. 9).

Lo anterior "significa que las personas cuentan con habilidades, destrezas, conocimientos y actitudes que pueden aplicar al utilizar los sistemas de información y comunicación" (Arras, Torres y García, 2011, p. 3).

A raíz del trabajo sobre competencias en TIC y rendimiento académico realizado durante 2009 en la Universidad de Salamanca (España), la Universidad Veracruzana y la Universidad Autónoma de Chihuahua (UACH) (México) (García y Arras, 2011), las competencias se clasificaron del siguiente modo: básicas, de aplicación, profundización y éticas. Posteriormente, para avanzar en el conocimiento de diversos programas académicos y en los entornos de educación virtual, dicha clasificación se complementó y se desarrollaron las categorías de competencias básicas, las cuales se refieren al manejo de las tecnologías, y las de aplicación, referentes al uso productivo de los programas y obtención de información (García y Arras, 2011, p. 5).

En cuanto a las competencias de profundización, son aquellas que permiten a las personas resolver problemas, crear trabajos originales, planear y organizar las actividades relacionadas con un proyecto determinado y comunicar el conocimiento obtenido mediante el uso eficaz de las herramientas digitales (García y Arras, 2011, p. 5). Dichas acciones implican análisis y toma de decisiones sobre el contenido de los mensajes que se obtienen vía las TIC. Ello significa que se utiliza la información eficazmente para cumplir un propósito específico, como la construcción de conocimiento sustentado (Jaramillo, Henning y Rincón, 2011, p. 142), el cual supone que la persona elige la información, luego la analiza desde una postura reflexiva, para después reconstruirla desde la perspectiva personal del conocimiento (Mañas y Roig, 2019, p. 82).

Las competencias de trabajo colaborativo involucran las dimensiones individual y social de la formación. Esta última incluye aprender en comunidad y ser capaz de interactuar y colaborar para construir conocimientos (Cabero, 2016, p. 3) mediante procesos de intercambio y construcción del saber, a la vez que se desarrollan competencias de aprendizaje permanente con el uso de las TIC (Arras, Bordas y Gutiérrez, 2017). 


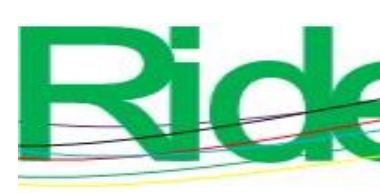

Revista Iberoamericana para la
Investigación y el Desarrollo Educativo
ISSN $2007-7467$

Por su parte, las competencias de aprendizaje permanente implican:

La habilidad para iniciar el aprendizaje y persistir en él, organizarlo, gestionar el tiempo y la información, ya sea individualmente o en grupos. (...) Adquirir, procesar y asimilar nuevos conocimientos y capacidades, así como utilizar experiencias vitales y de aprendizaje anteriores para aplicar los nuevos conocimientos y capacidades en diversos contextos (Comunidades Europeas, 2007, p. 8)

Estas habilidades, junto con las digitales, las de gestión de información, trabajo en red y éticas, se configuran como herramientas importantes en todos los niveles educativos (García, 2017). Las competencias digitales son clave para la educación actual. No obstante, investigaciones recientes han observado que las TIC son poco utilizadas para fines académicos, pues, en su mayoría, los estudiantes universitarios las usan durante sus tiempos de ocio; de tal suerte que el reto mayor es dar el salto al siguiente nivel de aprendizaje de los alumnos (Paredes, 2019, p. 1): que adquieran habilidades para construir conocimiento y que este proceso se fragüe a lo largo de la vida.

Las competencias éticas remiten a acciones guiadas por principios morales y valores como respeto, responsabilidad, honestidad, ética profesional y personal. El uso de las TIC debe ser responsable y ceñirse a la legalidad (Hirsch, 2005; Organización de las Naciones Unidas para la Educación, Ciencia y la Cultura [Unesco], 2008). Esto es: usar correctamente las fuentes de información; reconocer los derechos de autor, evitar la piratería y el plagio (Marcial, 2017).

El proceso de aprendizaje y adquisición de competencias implica la interpretación de los sujetos desde sus propias vivencias. De ahí la importancia del concepto de percepción. Esta, además de ser un proceso cognoscitivo, es una forma de conocer el mundo. Es un proceso complejo; en él confluyen la información que el mundo entrega, aspectos fisiológicos y las experiencias de quienes perciben (Moreno, Nelly y García, 2013, p. 445). Los juicios, característica básica de la percepción, constituyen procesos psíquico-cognitivos interactivos en los que interviene un componente vivencial (Villarruel, 2015, p. 41), condición que, desde ciertos contextos educativos, sitúa las percepciones como derivaciones de las experiencias. En tal sentido, los estudiantes autoevalúan sus competencias en TIC, autoevaluaciones que luego se contrastan con la opinión de los docentes, quienes son los facilitadores de la formación en el entorno virtual y disponen de criterios para comparar la autopercepción de los alumnos con los 


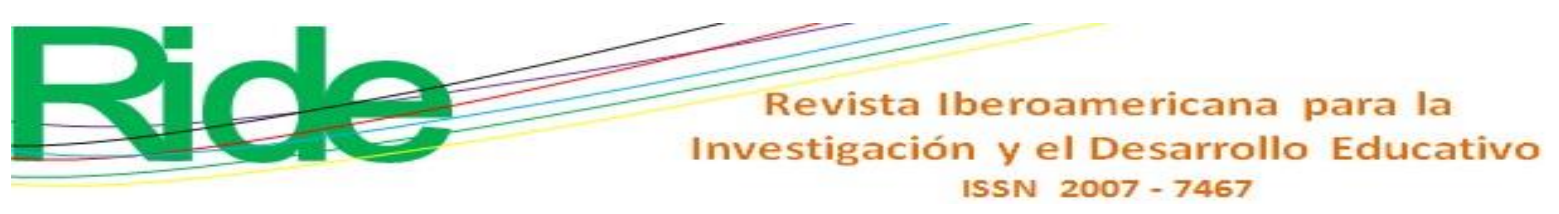

resultados de su aprendizaje, que son la evidencia de sus saberes y dominios (Cruz y Quiñonez, 2012).

El trabajo aquí expuesto coteja las percepciones estudiantiles frente a las evaluaciones docentes; los resultados de esta comparación constituyen una información relevante para establecer los aspectos que requieren reforzarse en los trayectos de formación, con el fin de lograr avanzar en el dominio de las competencias que permitirán a los estudiantes desarrollarse mejor en la vida profesional.

La figura 1 muestra los sujetos del aprendizaje — docentes y estudiantes-, quienes perciben e interpretan el mundo. En este, aplican y generan saberes; mejoran sus competencias a partir de reinterpretaciones e interconexiones entre los objetos cognoscitivos y los sujetos cognoscentes. Tal proceso es mediado por las tecnologías de los diversos entornos; en el caso aquí estudiado, el ambiente de las TIC.

Figura 1. Entornos de e-aprendizaje

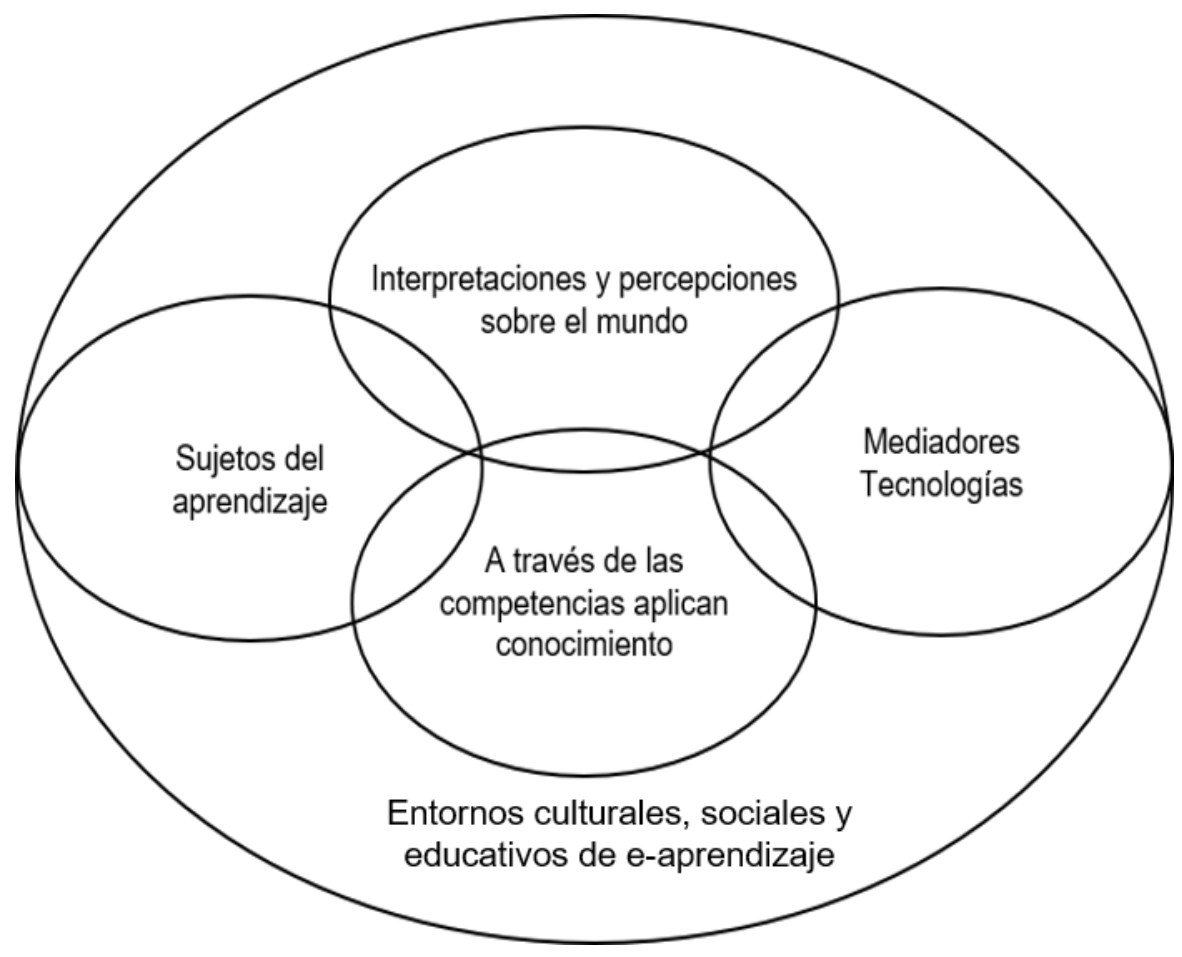

Fuente: Elaboración propia 


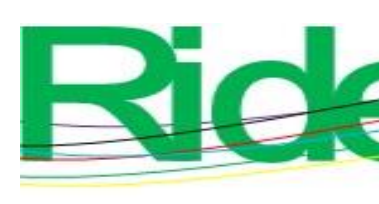

Revista Iberoamericana para la Investigación y el Desarrollo Educativo ISSN $2007-7467$

\section{Justificación}

Esta investigación deriva de anteriores estudios que han establecido la importancia del aprendizaje en la era digital, así como el valor que tiene la manifestación de competencias en TIC por parte de los estudiantes. Para las instituciones educativas es necesario contar con información sustentada sobre el dominio real que tienen los estudiantes de dichas competencias. Esta investigación atraviesa dos universos valorativos: el de los alumnos, que consideran tener competencia digital; y el de los docentes, quienes conocen los trabajos de sus estudiantes y los resultados obtenidos. De modo que la indagación ha arribado a ciertos resultados y conclusiones, ha generado determinada información, moviéndose entre esas dos valoraciones que giran en torno a un mismo tema: las competencias digitales de los estudiantes. Aunque los estudiantes se declaran competentes en TIC, es muy probable que a esa competencia le falte un mayor dominio y profundidad (López et al., 2017), así como un enfoque en el área académica, pues es bien sabido que los alumnos utilizan las TIC con fines de entretenimiento (Paredes, 2019, p. 2). De allí la importancia de comparar su percepción con la de los docentes y encontrar las posibles brechas que se necesiten subsanar. El hecho es que la presente investigación cumple con el cometido de develar una problemática específica, y en esa acción reveladora radica su valor y justificación.

En suma, analizar la trascendencia del uso de las TIC para profundizar en la construcción del conocimiento permanente, colaborativo y conectivo es fundamental para las instituciones de educación superior, ya que estas ejercen un papel central en la formación de sujetos cognoscentes, los cuales tendrán la responsabilidad del futuro de la humanidad y la necesidad de participar en la economía mundial. Así, es indispensable reflexionar y ser críticos ante los procesos académicos; considerarlos como áreas de oportunidad para mejorar los ambientes donde el ser humano se conecta consigo mismo y con el mundo. Por lo demás, la información generada por este estudio permite a la institución educativa y a los docentes contar con datos que pueden propiciar la reflexión sobre su práctica, así como atender aquellos aspectos que se consideren como áreas de oportunidad para los programas virtuales de formación universitaria.

\section{Objetivo}

Comparar la percepción que tienen los docentes y alumnos de e-aprendizaje sobre las competencias en TIC de los estudiantes. 


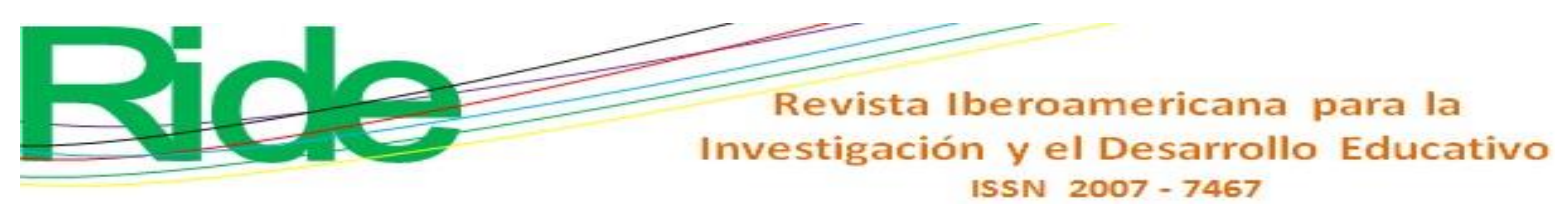

\section{Planteamiento del problema}

¿Se presentan diferencias entre la percepción de los docentes y la de los alumnos respecto a las competencias en TIC de los estudiantes?

\section{Hipótesis}

Hay diferencia entre la percepción que tienen los estudiantes sobre sus competencias en TIC y las que demuestran en sus trabajos; hay contraste entre las percepciones de docentes y alumnos sobre las competencias en TIC de los segundos. Las consideraciones de los formadores se basan en ciertas premisas que se enlistan a continuación:

- Los alumnos no apoyan sus documentos con imágenes o videos (Jaramillo et al., 2011, p. 141).

- Utilizan el buscador Google general más que el Google Académico a la hora de recopilar información (Jaramillo et al., 2011, p. 140).

- Falta en los alumnos el conocimiento indispensable para resolver problemas conceptuales y contribuir a la creación del conocimiento (Álvarez, Núñez y Rodríguez, 2017; Jaramillo et al., 2011, p. 140).

- Los jóvenes muestran carencias digitales para compartir y discutir en colaboración con otras personas a través de redes sociales y plataformas (Álvarez et al., 2017).

- Los estudiantes no utilizan referencias bibliográficas ni citan las fuentes consultadas (Jaramillo et al., 2011, p. 142).

\section{Materiales y método}

Esta investigación se realizó a partir de un estudio de caso, "el cual contribuye a ampliar y profundizar el conocimiento con respecto a individuos y grupos, así como organizaciones y fenómenos relacionados" (Yin, 2003, p. 4). Los métodos utilizados fueron el analítico-sintético y el teórico-deductivo. Asimismo, la investigación fue de naturaleza cuantitativa, ya que recoge datos a través de escalas. Es de tipo descriptivo, metodología aplicada en campo y apoyada en fuentes bibliográficas. 


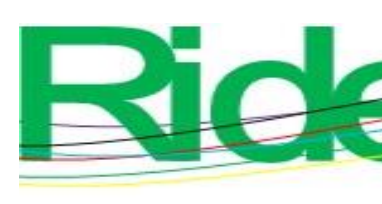

\section{Revista Iberoamericana para la Investigación y el Desarrollo Educativo ISSN $2007-7467$}

\section{Técnicas}

Como técnicas de acopio de la información se utilizaron la documental (bibliografía) y estadística, así como la encuesta por red o dispositivos móviles. Mediante las técnicas bibliográficas se recopiló la información para construir el marco teórico y realizar la discusión de resultados. La encuesta estuvo integrada por ítems relativos a la percepción de los estudiantes y docentes sobre el desarrollo de indicadores de competencias en TIC, a través de una escala donde 0 = Nada competente, 1 = Poco competente, 2 = Bastante competente y 3 = Muy competente. Al diseñar el cuestionario, se retomó el utilizado en el estudio de competencias en TIC de las universidades de Salamanca (España), Veracruzana y la UACH (México) (García y Arras, 2011). Sin embargo, se operaron aspectos cuya presencia estaba subyacente en preguntas, de manera que se trabajaron 24 ítems que evidencian especialmente aspectos relacionados con las competencias de aplicación y de profundización, al tiempo que se analizan por separado las de aprendizaje permanente y trabajo colaborativo. El instrumento de medición se aplicó vía correo electrónico, WhatsApp y Facebook; se respondió de manera interactiva por medio del dispositivo electrónico de preferencia para la persona que lo respondió.

Con respecto al análisis estadístico de los datos, se utilizó el paquete Statistical Package for the Social Sciences (SPSS versión 20.0), un software de analítica predictiva (International Business Machines [IBM], 2016).

\section{Universos de estudio}

La presente investigación se realizó en la Facultad de Contaduría y Administración (FCA) de la Universidad Autónoma de Chihuahua (UACH). La universidad se fundó el 8 de diciembre de 1954 y en 1968 logró su autonomía (Universidad Autónoma de Chihuahua , 2018). La UACH se compone de 16 unidades académicas, entre las cuales se encuentra la FCA, instituida el 18 de diciembre de 1958. En la actualidad, ofrece cinco carreras profesionales, de las cuales una es ofertada en su totalidad tanto en modalidad virtual como presencial; las demás carreras pueden cursarse de manera mixta, dependiendo de las materias. Asimismo, la FCA ofrece diez posgrados; de estos, seis se imparten, en su totalidad, tanto presencial como virtualmente; lo anterior permite tener presencia global.

Los universos de estudio fueron conformados por 389 alumnos y 103 docentes de licenciatura de la modalidad virtual, en 2017. Para obtener las muestras se utilizó la siguiente fórmula: 


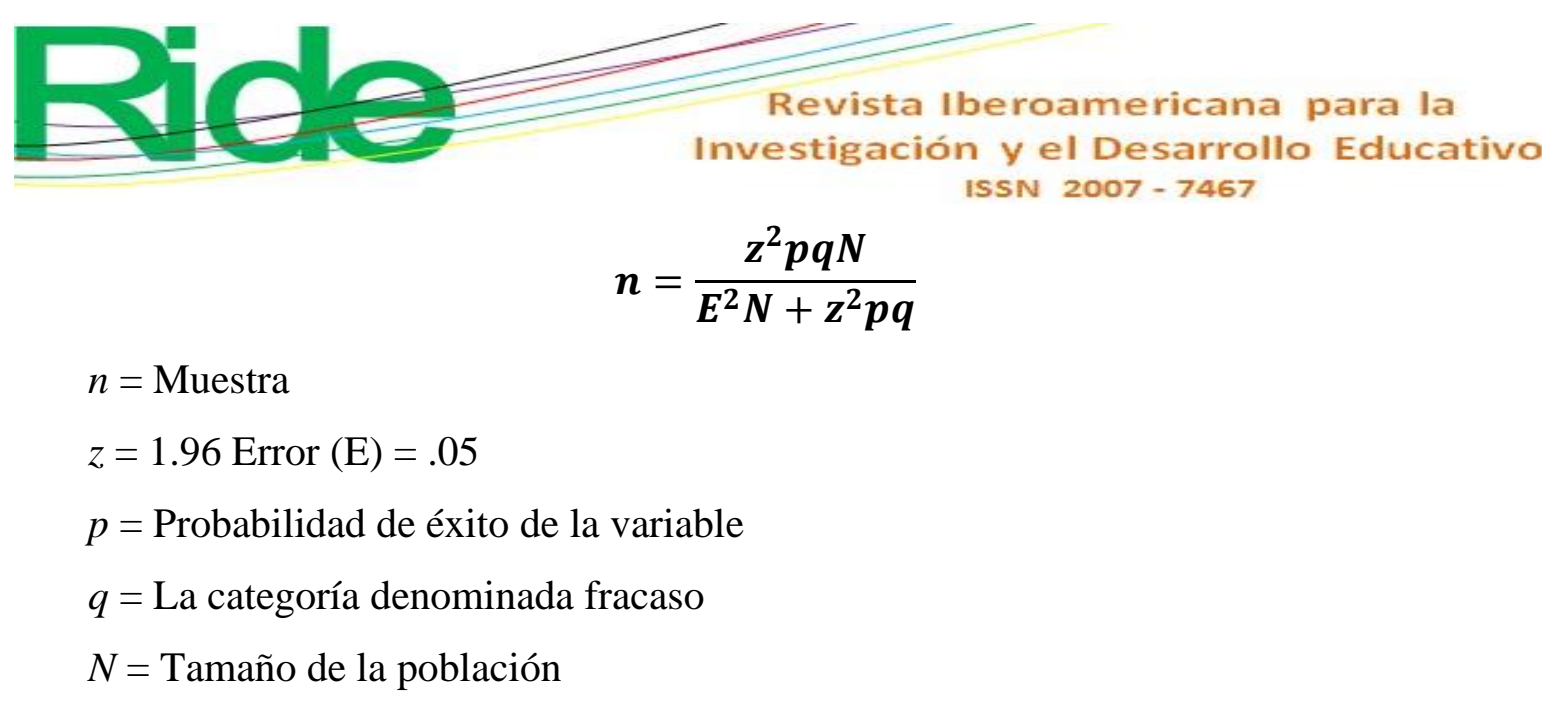

La muestra de estudiantes fue de 151 (70.19\% mujeres y $29.80 \%$ hombres), de una población de 389; asimismo, de 103 docentes (61.64 \% mujeres y $38.35 \%$ hombres), la muestra resultante fue de 73 (ver tabla 1).

Tabla 1. Tamaño de las muestras

\begin{tabular}{|c|c|c|}
\hline Año & $\begin{array}{c}\text { Muestra } \\
\text { estudiantes }\end{array}$ & $\begin{array}{c}\text { Muestra } \\
\text { docentes }\end{array}$ \\
\hline 2017 & 151 & 73 \\
\hline
\end{tabular}

Fuente: Elaboración propia

\section{Confiabilidad del instrumento}

Una de las pruebas más usadas para medir el grado de confiabilidad de una escala es el coeficiente alfa de Cronbach (Landero y González, 2006, p. 156). En este trabajo proporcionó el valor de 0.918 para docentes y 0.919 para los alumnos, lo que denota que los resultados son confiables, ya que 0.7 es aceptable, 0.8 bueno y 0.9 excelente (Frías, 2014) (ver tabla 2). 


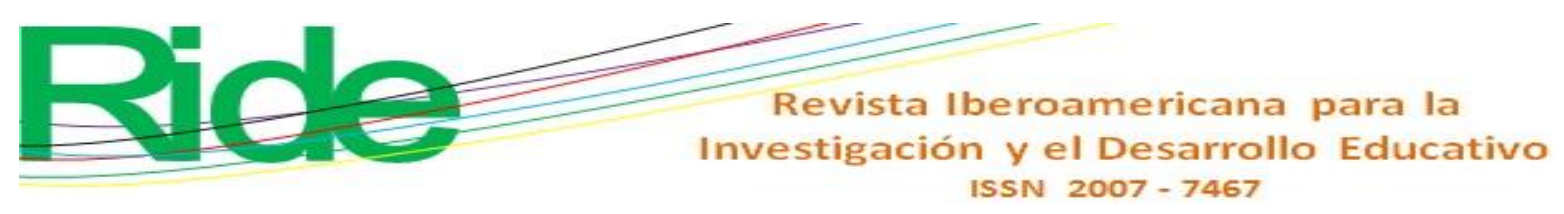

Tabla 2. Estadísticos de fiabilidad del instrumento

\begin{tabular}{|c|c|c|}
\hline Competencias & Alfa de Cronbach & Número de ítems en el cuestionario \\
\hline Básicas & 0.734 & 3 \\
\hline Aplicación & 0.803 & 7 \\
\hline Profundización & 0.916 & 4 \\
\hline $\begin{array}{c}\text { Trabajo } \\
\text { Colaborativo }\end{array}$ & 0.816 & 2 \\
\hline $\begin{array}{c}\text { Aprendizaje } \\
\text { Permanente } \\
\text { Ética }\end{array}$ & 0.754 & 2 \\
\hline
\end{tabular}

Fuente: Elaboración propia

\section{Resultados}

A continuación, se muestra un comparativo de la percepción que tienen los estudiantes y docentes sobre sus competencias en TIC, representadas por medias, calculando en cada caso el valor de $\mathrm{x}^{2}$ a partir de datos observables y los datos experimentales; así se obtuvo el valor en cada caso; se asume un riesgo de margen de error $0.05 \%$ ( $p<0.05)$. Por último, se generó un gráfico comparativo entre la totalidad de las competencias y cómo fue la percepción de su desarrollo en cada uno de los universos.

\section{Competencias básicas}

Tres ítems relativos al manejo de programas y las presentaciones elaboradas por los estudiantes en su quehacer académico integraron el conjunto de competencias básicas. 


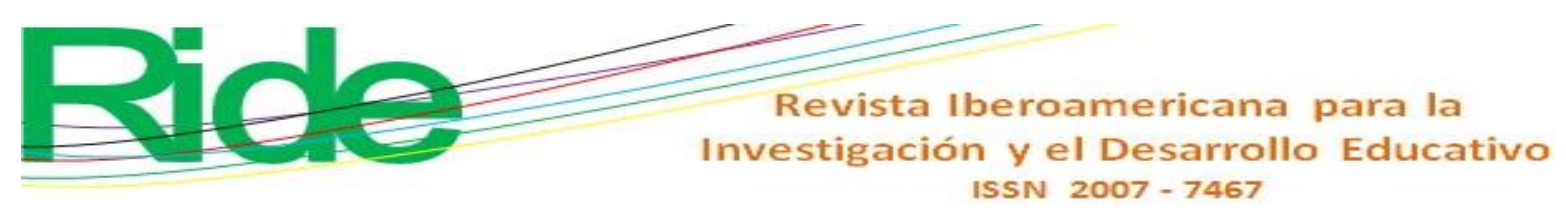

Tabla 3. Tabla comparativa del desarrollo de competencias básicas percibidas por alumnos versus docentes

\begin{tabular}{|l|c|c|c|}
\hline & Alumnos & Docentes & $\mathbf{x}^{\mathbf{2}}$ \\
\hline $\begin{array}{l}\text { 1) Manejo efectivamente el Word, Excel, } \\
\text { PowerPoint y otros programas. }\end{array}$ & 2.14 & 1.81 & 0.003 \\
\hline $\begin{array}{l}\text { 2) Utilizo herramientas digitales para mis } \\
\text { presentaciones académicas. }\end{array}$ & 2.03 & 1.74 & 0.004 \\
\hline 3) Utilizo videos en mis presentaciones. & 1.38 & 1.01 & 0.017 \\
\hline
\end{tabular}

Fuente: Elaboración propia

La tabla 3 muestra que los alumnos se consideraron bastante competentes en el manejo de Word, Excel, PowerPoint y otros programas, así como en el uso de herramientas digitales para sus presentaciones académicas. Al comparar las respuestas de los docentes con las de los estudiantes en estos ítems, se observó una diferencia significativa $\left(x^{2}=0.003\right.$ y 0.004$)$ a favor de los últimos.

El ítem relacionado con la utilización de videos en las presentaciones fue el valorado más bajo; asimismo, presentó un valor de significancia de 0.017 a favor de los alumnos, quienes consideraron tener dicha competencia.

\section{Competencias de aplicación}

Seis ítems conformaron las competencias de aplicación. Estos reflejan el uso de bases de datos científicas y aplicaciones específicas de Word para sus trabajos académicos. 


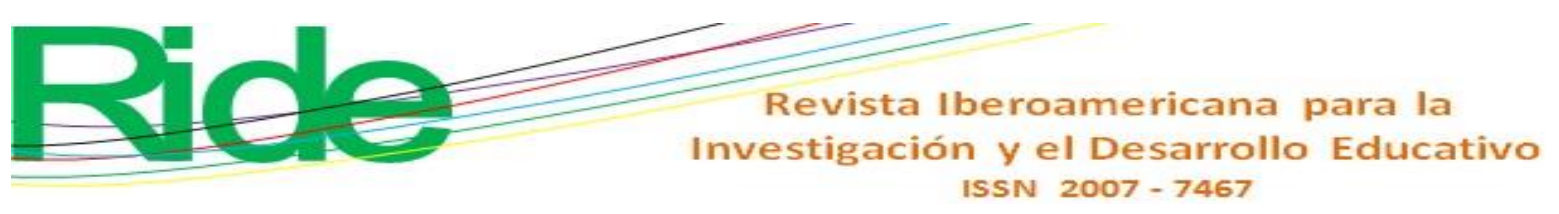

Tabla 4. Tabla comparativa del desarrollo de competencias de aplicación percibidas por alumnos versus docentes

\begin{tabular}{|l|c|c|c|}
\hline & Alumnos & Docentes & $\mathbf{x}^{\mathbf{2}}$ \\
\hline $\begin{array}{l}\text { 4) Uso modelos y simulaciones para explorar temas } \\
\text { complejos. }\end{array}$ & 1.37 & 0.86 & 0.000 \\
\hline $\begin{array}{l}\text { 5) Para estar mejor informado/a utilizo bases de } \\
\text { datos científicas en la búsqueda de respuestas a las } \\
\text { preguntas que surgen de las materias que curso. }\end{array}$ & 1.75 & 0.86 & 0.000 \\
\hline $\begin{array}{l}\text { 6) Para entregar trabajos académicos realizo } \\
\text { búsquedas de información con las bases de datos } \\
\text { científicas con las que cuenta la UACH. }\end{array}$ & 1.25 & 0.74 & 0.000 \\
\hline $\begin{array}{l}\text { 7) Para entregar trabajos académicos realizo } \\
\text { búsquedas de información con Google. }\end{array}$ & 2.41 & 2.41 & 0.256 \\
\hline $\begin{array}{l}\text { 8) Para entregar trabajos académicos realizo } \\
\text { búsquedas de información con Google Académico. }\end{array}$ & 1.75 & 1.33 & 0.004 \\
\hline $\begin{array}{l}\text { 9) Integro las referencias y bibliografía en una tarea } \\
\text { académica en automático utilizando el Word. }\end{array}$ & 1.95 & 1.12 & 0.000 \\
\hline
\end{tabular}

Fuente: Elaboración propia

Como se puede observar en la tabla 4, al comparar las valoraciones de alumnos y docentes, cinco de estas presentaron una diferencia significativa $\left(\mathrm{x}^{2}\right)$, lo cual refleja una brecha entre la percepción de los estudiantes y los docentes, a excepción del ítem siete. En relación con el uso de Google para buscar información y entregar trabajos académicos, ambos colectivos asignaron una calificación de "Bastante competente", con una media por igual de 2.41.

\section{Competencias de profundización}

Las competencias de profundización se integraron en siete ítems que remiten a capacidades analíticas, sintéticas, y de problematización y construcción del conocimiento. 


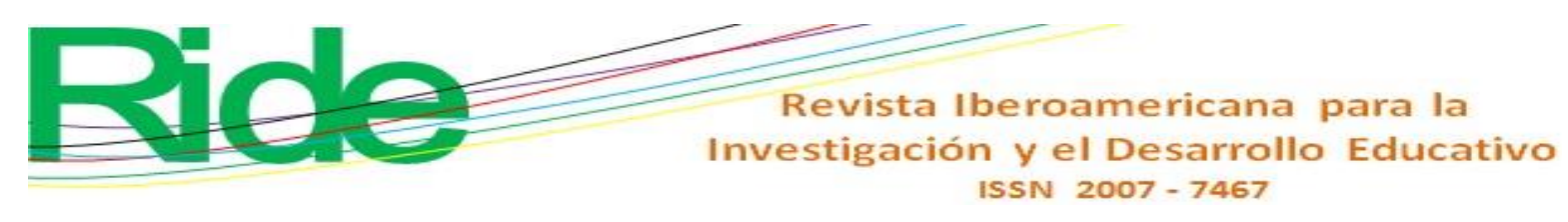

Tabla 5. Tabla comparativa del desarrollo de competencias de profundización percibidas por alumnos versus docentes

\begin{tabular}{|l|c|c|c|}
\hline & Alumnos & Docentes & $\mathbf{x}^{\mathbf{2}}$ \\
\hline $\begin{array}{l}\text { 10) Leo cuando menos cinco artículos científicos, } \\
\text { utilizando las TIC, para realizar una tarea. }\end{array}$ & 1.75 & 0.76 & 0.000 \\
\hline $\begin{array}{l}\text { 11) Desgloso los elementos del artículo y hago } \\
\text { comentarios para enriquecer mi trabajo académico. }\end{array}$ & 1.74 & 0.99 & 0.000 \\
\hline $\begin{array}{l}\text { 12) Creo trabajos originales como medio de } \\
\text { expresión personal, utilizando las TIC. }\end{array}$ & 2.03 & 1.12 & 0.000 \\
\hline $\begin{array}{l}\text { 13) Tengo habilidad para resolver problemas } \\
\text { utilizando las TIC. }\end{array}$ & 2.04 & 1.49 & 0.000 \\
\hline $\begin{array}{l}\text { 14) Tengo la capacidad de construir conceptos } \\
\text { propios a partir de las definiciones de otros autores. }\end{array}$ & 1.95 & 1.28 & 0.000 \\
\hline $\begin{array}{l}\text { 15) Tengo las habilidades y el conocimiento que me } \\
\text { permiten realizar un proyecto de investigación } \\
\text { utilizando las TIC. }\end{array}$ & 1.98 & 1.34 & 0.000 \\
\hline $\begin{array}{l}\text { 16) Tengo habilidades para generar preguntas clave } \\
\text { y problemas, formulándolos con claridad y } \\
\text { precisión. }\end{array}$ & 1.85 & 1.23 & 0.000 \\
\hline
\end{tabular}

Fuente: Elaboración propia

Los ítems sobre lectura de artículos científicos y consulta en bases de datos científicas que aparecen en las competencias de aplicación fueron evaluados de la misma manera por los estudiantes (1.75), lo que proporcionaría consistencia a sus respuestas. Se asignaron, en el ítem 10, una calificación cercana al "Bastante competente", mientras que los docentes establecieron 0.76, es decir, "Poco competente" (Ver tabla 5).

\section{Competencias de trabajo colaborativo}

Las competencias de trabajo colaborativo están compuestas por cuatro ítems relativos a este tipo de responsabilidad entre los estudiantes de licenciatura virtual. 


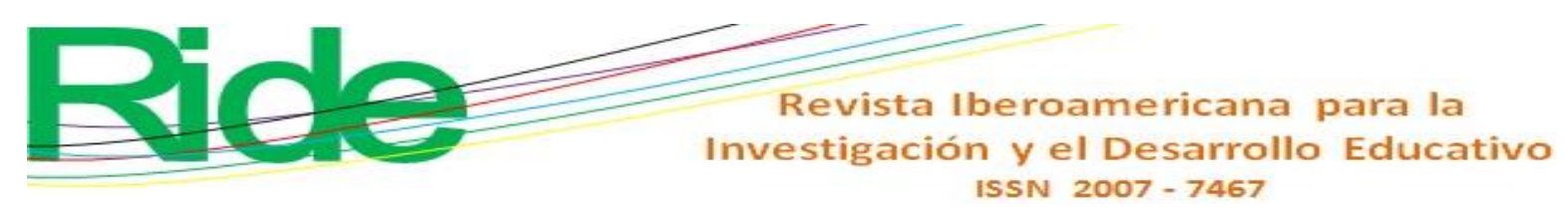

Tabla 6. Tabla comparativa del desarrollo de competencias de trabajo colaborativo percibidas por alumnos versus docentes

\begin{tabular}{|l|c|c|c|}
\hline & Alumnos & Docentes & $\mathbf{x}^{\mathbf{2}}$ \\
\hline $\begin{array}{l}\text { 17) Realizo trabajos académicos en equipo } \\
\text { empleando variedad de recursos digitales. }\end{array}$ & 1.98 & 1.50 & 0.000 \\
\hline $\begin{array}{l}\text { 18) Participo en grupos que desarrollan proyectos } \\
\text { para la producción de trabajos o resolución de } \\
\text { problemas. }\end{array}$ & 1.41 & 1.28 & 0.088 \\
\hline $\begin{array}{l}\text { 19) Realizo trabajo colaborativo con mis } \\
\text { compañeros por medios de las TIC }\end{array}$ & 1.88 & 1.54 & 0.004 \\
\hline $\begin{array}{l}\text { 20) Considero que es importante trabajar en equipo } \\
\text { utilizando las TIC }\end{array}$ & 2.29 & 1.68 & 0.000 \\
\hline
\end{tabular}

Fuente: Elaboración propia

Los resultados de la tabla 6 muestran, que los académicos consideraron que los estudiantes son poco competentes para participar en grupos y realizar trabajo colaborativo (ítem 17). Por su parte, los alumnos se evaluaron, especialmente en la realización de trabajo colaborativo (ítem 19), como bastante competentes. Aunque la pregunta es muy similar, la respuesta varía. Además, los estudiantes ponderaron trabajar en equipo utilizando las TIC, y la diferencia respecto a los docentes fue significativa, con una $\mathrm{x}^{2}$ de 0.000 .

\section{Competencias de aprendizaje permanente}

Las competencias de aprendizaje permanente se configuraron en dos ítems que enuncian estas capacidades. 


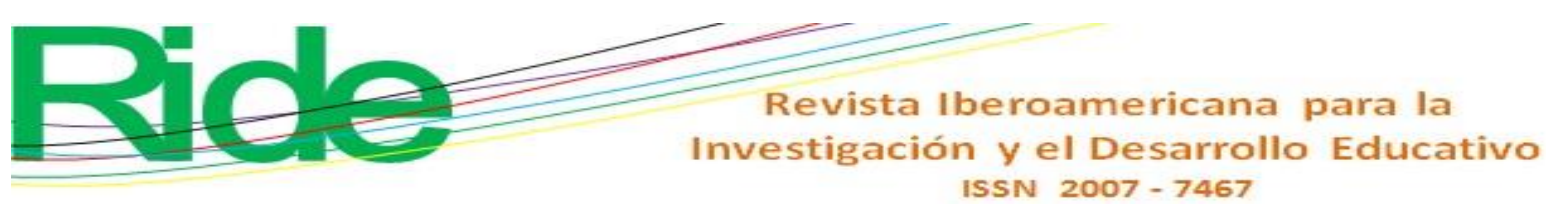

Tabla 7. Tabla comparativa del desarrollo de competencias de aprendizaje permanente percibidas por alumnos versus docentes

\begin{tabular}{|l|c|c|c|}
\hline & Alumnos & Docentes & $\mathbf{x}^{2}$ \\
\hline $\begin{array}{l}\text { 21) Estoy abierta/o a formas de pensamiento } \\
\text { diferentes a la mía que me permitan enriquecer el } \\
\text { conocimiento. }\end{array}$ & 2.61 & 1.86 & 0.000 \\
\hline $\begin{array}{l}\text { 22) Utilizo las TIC para aprender de manera } \\
\text { permanente. }\end{array}$ & 2.25 & 1.82 & 0.000 \\
\hline
\end{tabular}

Fuente: Elaboración propia

En torno a las competencias de aprendizaje permanente, se obtuvo una valoración con diferencia significativa a favor de los alumnos en ambos ítems; sin embargo, ambas calificaciones están cerca de "Bastante competente" y con tendencia por parte de los estudiantes a la nota de "Muy competente" (véase tabla 7).

\section{Competencias éticas}

Las competencias éticas se integraron en dos ítems que plantean el respeto y reconocimiento al trabajo de otros e implican nociones de derechos autorales.

Tabla 8. Tabla comparativa del desarrollo de competencias éticas percibidas por alumnos versus docentes

\begin{tabular}{|l|c|c|c|}
\hline & Alumnos & Docentes & $\mathbf{x}^{2}$ \\
\hline $\begin{array}{l}\text { 23) Al realizar una tarea académica siempre cito al } \\
\text { autor o autores que escribieron los documentos que } \\
\text { utilizo como referencia, ya sea de manera textual o } \\
\text { de parafraseo. }\end{array}$ & 1.93 & 1.11 & 0.000 \\
\hline $\begin{array}{l}\text { 24) Utilizo las TIC para aprender de otros y } \\
\text { reconocerles su trabajo al citarles. }\end{array}$ & 1.96 & 1.11 & 0.000 \\
\hline
\end{tabular}

Fuente: Elaboración propia

La tabla 8 refleja que los estudiantes se percibieron como bastante competentes en capacidades éticas. Por su parte, los académicos, pese a la diferencia significativa de $\mathrm{x}^{2}$ de 0.000 a favor de los alumnos, adjudicaron a estos la calificación de "Poco competente". Tal estimación significa que los estudiantes no siempre citan sus fuentes ni ofrecen referencias bibliográficas en 


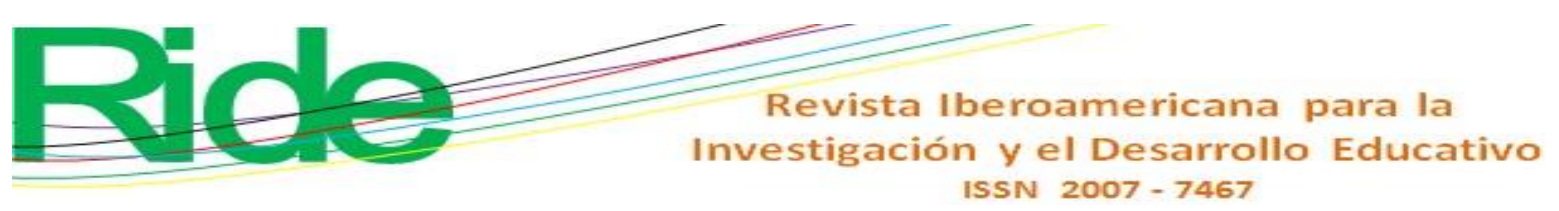

sus trabajos. Dos visiones, dos posturas entre quien considera que realiza la acción y quien se encarga de evaluar el desempeño.

\section{Visión general del desarrollo de competencias en TIC}

La disparidad entre la percepción estudiantil y la docente hace que surjan varios cuestionamientos, por ejemplo, ¿cuáles deberían ser las estrategias académicas para formar personas que actúen éticamente, en concreto frente a los derechos de autor?, ¿qué peso tendrá en la calificación de cada trabajo citar o no las fuentes? En última instancia, el tema trasciende hasta el sentido fundamental de la educación, en cómo profundizar en los procesos formativos de ciudadanos honestos, con valores, mediante la educación, en cualquiera de sus modalidades, presencial y virtual. En la figura 2 se muestra una visión general de la percepción que tienen tanto los alumnos como los docentes en relación con el desarrollo de sus competencias en TIC.

Figura 2. Gráfico comparativo de competencias en TIC entre alumnos y docentes alumnos Docentes

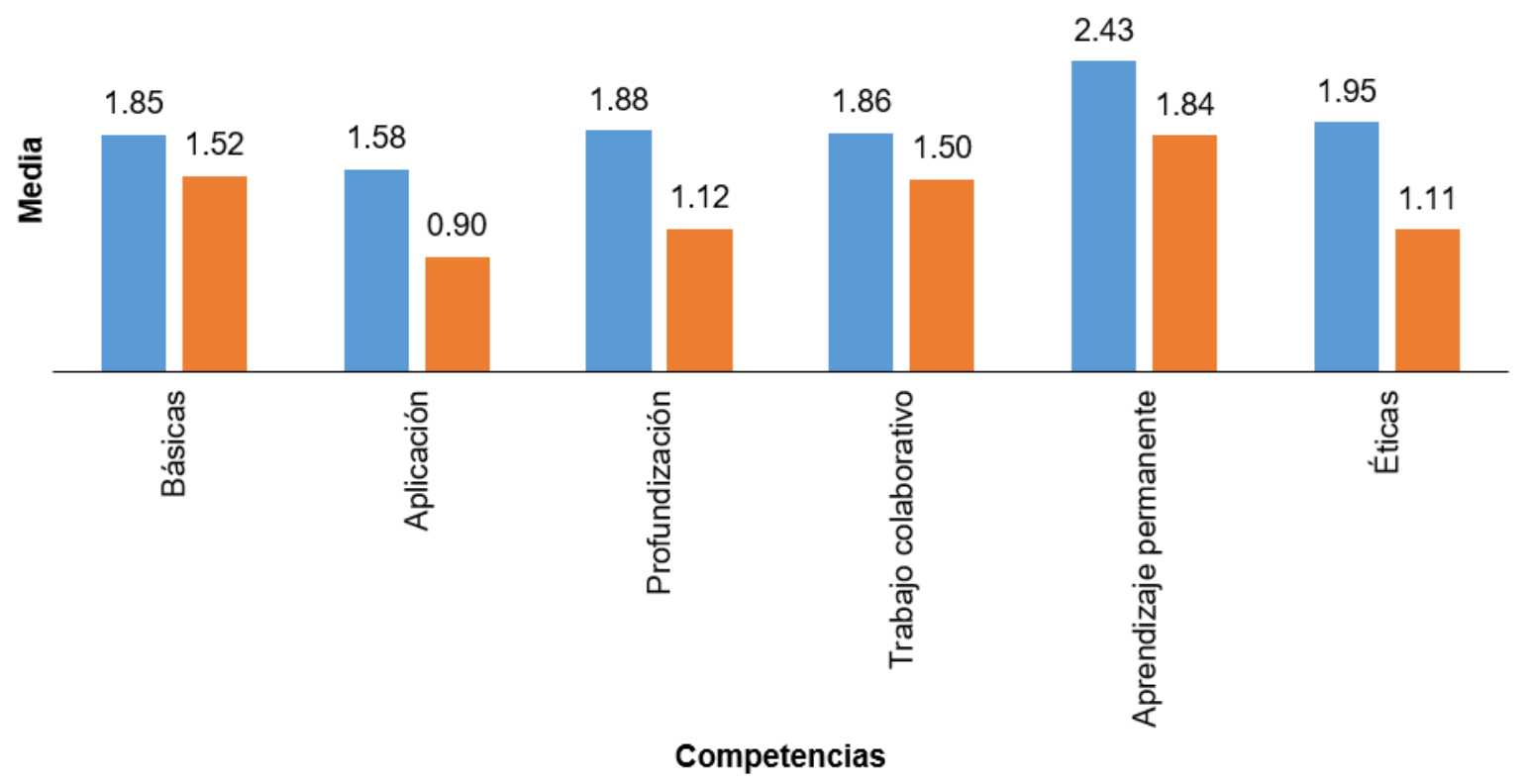

Fuente: Elaboración propia 


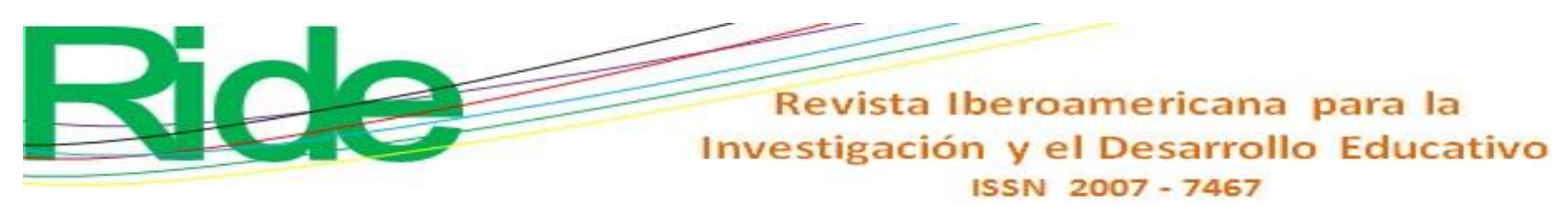

\section{Discusión}

El estudio analiza la percepción que tienen los estudiantes sobre la percepción de sus competencias en TIC y las compara con la visión de los docentes sobre las competencias que aquellos aducen tener; el hilo conductor de esta investigación son las hipótesis que enseguida se retoman:

- Los alumnos no apoyan sus documentos con imágenes o videos (Jaramillo et al., 2011, p. 141).

En torno a las competencias básicas destaca el hecho de que los discentes valoran estas con una distancia entre ser "Bastante competente" y "Muy competente", y los docentes perciben un espacio mayor para la mejora de los escolares, por lo que se ha de considerar la importancia de enfatizar más en sus habilidades de manejo de las TIC y vincularlas con los objetivos del aprendizaje (Ramírez y Barragán, 2018, p. 94), lo cual es relevante debido a que cursan la licenciatura de manera virtual. Los estudiantes, menciona Falco (2017, p. 64), desde una edad muy temprana, acceden con soltura a información que da prioridad a imágenes, de las cuales obtienen conocimiento procesando información discontinua y no lineal; por lo anterior, los docentes pueden exigir más con el fin de que los alumnos aprendan aprovechando las diferentes técnicas que ofrecen los ordenadores (Plaza de la Hoz, 2018). Difiere dicha apreciación con la percepción de los docentes y que lleva a la comprobación parcial de la hipótesis.

- Utilizan Google general más que el Google Académico como buscador de información (Jaramillo et al., 2011, p. 140).

En lo que concierne a las competencias de aplicación, los estudiantes, en promedio, las evaluaron por arriba de la valoración que asignaron los catedráticos; aun así, no rebasaron la calificación de dos, que significa "Bastante competente". Este hecho evidencia la necesidad de reforzar las capacidades de aplicación, incluyendo el uso de Word para insertar las referencias bibliográficas y la bibliografía, además de enfatizar las búsquedas en bases de datos científicas para sustentar los trabajos académicos. Esto depende, en gran medida, de las exigencias y objetivos que establezca quien guía el proceso, ya que en investigaciones recientes se ha encontrado que la autopercepción sobre el uso de las tecnologías digitales de los estudiantes depende de los propósitos para los que las utiliza (Ramírez y Barragán, 2018, p. 98) y quienes guían el proceso han de establecer mayores requerimientos (Plaza de la Hoz, 2018, p. 498), entre ellos búsquedas en Google Académico y en bases de datos científicas, con el propósito de sustentar el conocimiento con fuentes confiables. Los resultados del análisis de esta competencia 


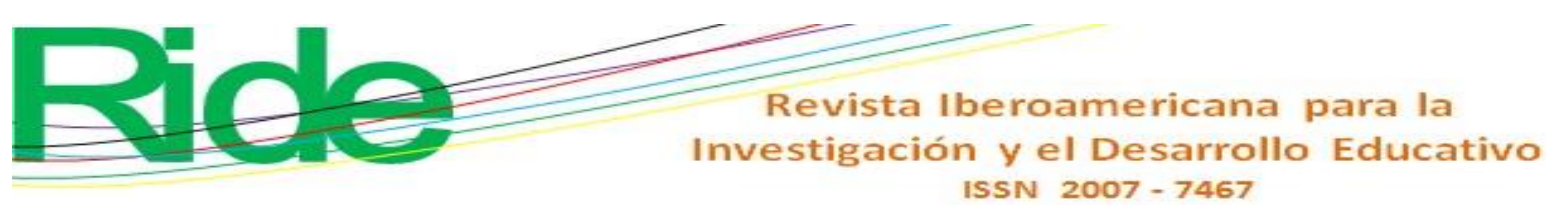

concuerdan con la hipótesis planteada. Dichos resultados concuerdan, asimismo, con los de Prendes, Solano, Serrano, González y Román (2018, p. 128), quienes hallaron que los alumnos, cuando quieren encontrar algo, utilizan el buscador de Google, blogs y páginas web.

- Falta en los alumnos el conocimiento indispensable para resolver problemas conceptuales y contribuir a la creación del conocimiento (Álvarez et al., 2017; Jaramillo et al., 2011, p. 140).

En torno a las competencias de profundización, los resultados muestran valoraciones asimétricas entre los estudiantes y los docentes, lo que obliga a replantear el quehacer del profesor, pues "para lograr la necesaria validez del diseño formativo, la evaluación ha de ser coherente con los objetivos de enseñanza y las competencias a desarrollar a través de una metodología didáctica adecuada" (Olmos y Rodríguez, 2010, p. 1). Si los docentes consideran que los alumnos no están adquiriendo las competencias de análisis, síntesis, construcción conceptual y generación de investigación, deberán asumir la corresponsabilidad en el proceso formativo para que sus estudiantes logren adquirir y desarrollar dichas habilidades. Este resultado de las competencias de profundización lleva a considerar que la hipótesis no se rechaza, pues la calificación que se asignan los estudiantes y la que otorgan los docentes refleja una valoración de poco competentes.

- Los jóvenes muestran carencias digitales para compartir y discutir en colaboración con otras personas a través de redes sociales y plataformas (Álvarez et al., 2017).

En ese mismo sentido aparecen los requerimientos del trabajo colaborativo que demandan las condiciones actuales de la educación y se necesita que los estudiantes mejoren sus competencias para participar en la construcción del conocimiento con el otro o los otros y, para ello, los procesos de enseñanza-aprendizaje han de prever y disponer, desde el diseño del material y de las actividades a desarrollar, la construcción del conocimiento interactivo (Santos y Tirado, 2019, p. 26); junto con esta práctica habrá que evaluar los procesos para realimentar el diseño de los métodos de aprendizaje y originar cambios actitudinales entre los alumnos, para que acepten colaborar más adecuadamente con sus compañeros, en equipos de trabajo y mediante las TIC (Hernández, Muñoz y González, 2018, p. 24). Asimismo, los docentes habrán de diseñar procesos en los que se exija el trabajo en equipo para avanzar en el aprendizaje y construcción del conocimiento en conjunto. En realidad, aunque los alumnos valoran el trabajo en equipo (ítem 20), de acuerdo con los resultados se realiza poco y se puede decir, siguiendo la hipótesis 


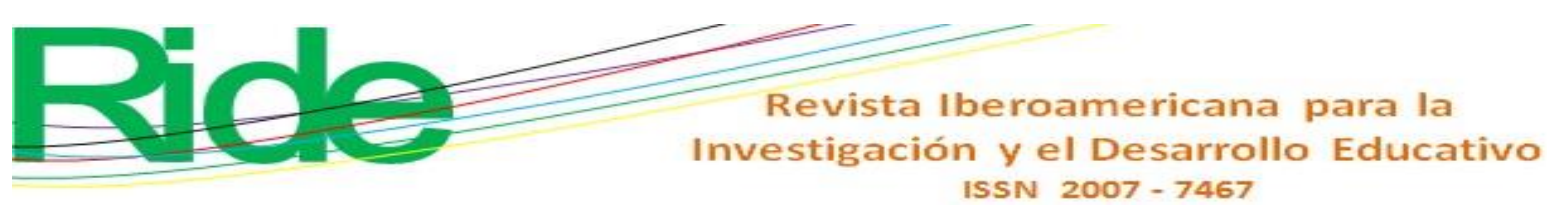

planteada, que los jóvenes muestran carencias digitales para compartir y discutir en colaboración con otras personas a través de redes sociales y plataformas.

En torno a las competencias en aprendizaje permanente, las valoraciones de los docentes se ubican en "Bastante competente", mientras que la de los alumnos en "Muy competente" para iniciar en el aprendizaje, organizarlo, adquirir conocimientos y aplicarlos en diversos contextos (Comunidades Europeas, 2007, p. 8), lo cual refleja la posesión de actitudes positivas hacia la adquisición permanente de conocimiento, herramienta importante en la educación (García, 2017) y además habla de una actitud positiva hacia el proceso de construcción de saberes a lo largo de la vida.

- Los estudiantes no utilizan referencias bibliográficas ni citan las fuentes consultadas (Jaramillo et al., 2011, p. 142).

Con respecto a las competencias éticas en el uso de TIC, se puede decir que los estudiantes se consideran bastante competentes y esto coincide con estudios recientes (Prendes et al., 2018), cuyos autores encontraron que dos de cada tres estudiantes universitarios aseguraron utilizar referencias y respetar los derechos de autor; sin embargo, de acuerdo con los docentes, en el caso objeto de estudio, no es así, lo que remite a la necesidad de recordar continuamente en la práctica académica y de investigación la importancia de citar adecuadamente el trabajo de los autores que se utilizan como sustento de las ideas y conceptos que se plantean en los documentos que se presentan para acreditar las asignaturas en la universidad o en otros escenarios donde participan los seres humanos. Sin embargo, la hipótesis se rechaza ya que ninguno la ha calificado con cero.

Es importante que los maestros exijan en los trabajos de los alumnos profundización en el tratamiento de los temas, construcción conceptual, habilidades analítico-sintéticas y citación de fuentes; asimismo, la información aquí obtenida puede ser utilizada para desarrollar estrategias que ayuden a mejorar las metodologías de enseñanza utilizadas y estas estén acordes al tercer milenio.

La comprensión de los procesos de adquisición de competencias desde la perspectiva de los sujetos del aprendizaje constituye información valiosa y abre la puerta a nuevas investigaciones sobre las prácticas educativas en los entornos de e-aprendizaje. Además, plantea el reto que tienen los docentes como actores del proceso formativo que demanda el establecimiento de mayores exigencias para los estudiantes con el propósito de que avancen en el dominio de las competencias en TIC que requieren las necesidades del mundo actual.

La presente investigación permitirá a los docentes, investigadores, administradores y los tomadores de decisión aprender acerca de la percepción que tienen los discentes, de cómo 


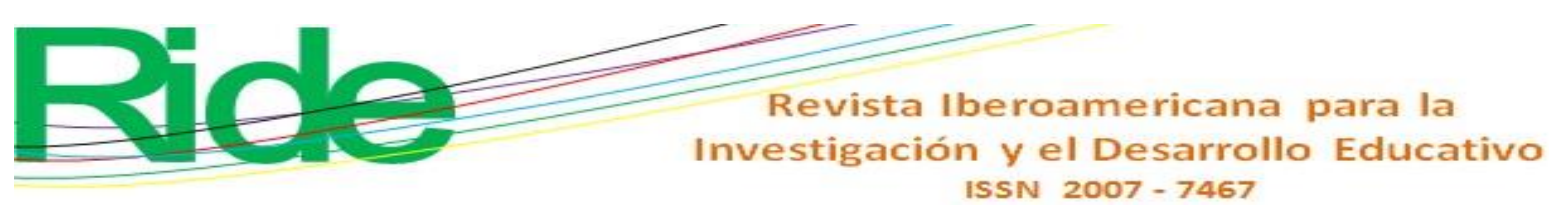

adquieren el conocimiento, y si este es suficiente para hacer frente a las condiciones laborales a las que se enfrentarán; además, es de gran relevancia el determinar las áreas de oportunidad para lograr un aprendizaje significativo a través del uso de las TIC.

\section{Conclusiones}

La presente investigación permite arribar a inferencias que atañen tanto a procesos educativos, en especial a la reciente eclosión de maneras y vías de aprendizaje, como a la reflexión sociopedagógica en torno a las capacidades que efectivamente se impulsan y enriquecen con las TIC. Una reflexión que debería estar guiada por el reconocimiento de los múltiples, complejos y revolucionarios efectos de la tecnología, pero, a la vez, nutrida por un sentido de ponderación que permita advertir las limitaciones reales que los sujetos concretos experimentan frente a la irrupción tecnológica.

Una importante proposición general que surge de esta indagación es el carácter incompleto, superficial y básico de las competencias digitales de los estudiantes. Lo más inquietante es que a esa limitación competencial se agrega que los aprendientes asumen una falsa creencia: la de sentirse bastante competentes en aspectos que verdaderamente desconocen o ni siquiera exploran, como son las bases de datos científicas y las fuentes primarias del discurso de las ciencias. Los alumnos, sujetos de aprendizaje con sus propias interpretaciones y percepciones, calificaron el desarrollo de sus competencias en TIC con puntajes más altos que los atribuidos por sus docentes. Resultaría improcedente alegar que los maestros percibieron con escasa objetividad el desarrollo competencial de sus alumnos, pues vale destacar que asignaron la calificación de "Bastante competente" en aprendizaje permanente, trabajo colaborativo y competencias básicas. No parece, entonces, que exista una carencia de objetividad de los docentes. En última instancia, son los maestros quienes conocen los trabajos elaborados por los estudiantes y cuentan con esos productos concretos (objetivos) para mostrar el nivel de desarrollo competencial de aquellos. Por lo que se produce una limitación doble: incompleta y superficial competencia digital y el no percatarse de esa limitación (la inconsciencia de la limitación).

Como lo evidencian los resultados, los estudiantes poseen un buen nivel de competencias digitales básicas; el problema surge en las competencias complejas, como son las de aplicación, profundización, trabajo colaborativo y éticas. Este fenómeno es análogo al que se experimenta con el desarrollo de las competencias lingüísticas. La inmensa mayoría de las personas está alfabetizada, sabe leer y escribir. Sin embargo, cuando se hace necesario desarrollar trabajos 


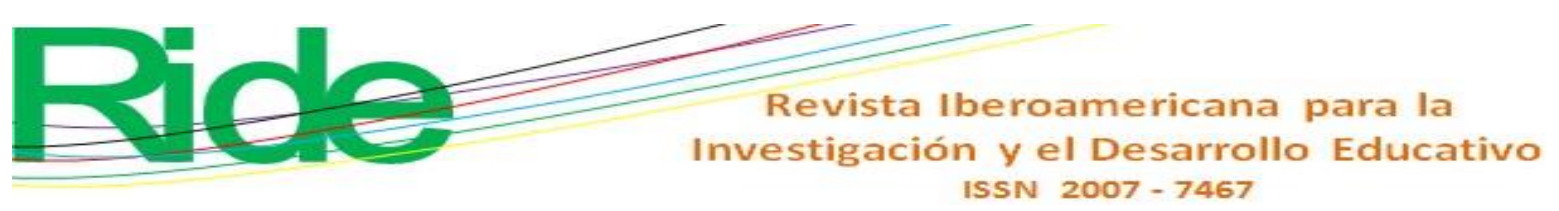

escritos originales o de investigación, las competencias son limitadas o inexistentes. Frente a la escritura - la tecnología fundante de la cultura moderna - la alfabetización básica resulta insuficiente. Igual ocurre con las competencias en TIC.

Dado lo anterior, y específicamente en relación con el trabajo colaborativo, los docentes señalan un déficit en el desarrollo de dicha competencia entre los estudiantes. Estos, sin embargo, no lo estiman así. Será porque no advierten que esa competencia la desarrollan, efectivamente, sin limitaciones en sus actividades de esparcimiento o diversión, pero no así en la actividad académica. Se trata de dos ámbitos distintos de ejercicio competencial. De ahí que en el ámbito académico sea necesario desarrollar habilidades que les permitan construir conocimientos y profundizar su saber mediante el trabajo colaborativo y la comunicación. Esto no solo implica un avance cognitivo, sino una forma de asumir y utilizar la tecnología informativa y comunicacional. En la medida en que los alumnos participen en la construcción colectiva del conocimiento y mantengan su percepción abierta hacia distintas formas de pensamiento, las TIC se perfilarán como un instrumento al servicio del saber, la humanización y la democracia. De otra manera, se alzarán como aparatos de devastación para el aprendizaje humano y la cultura.

Comparar la percepción de los alumnos y de los docentes con respecto al desarrollo de competencias en TIC de aquellos permitió percatarse de áreas de oportunidad en las instituciones de educación superior, en las cuales se generen estrategias para que, desde la planeación de las asignaturas, se establezca entre sus propósitos el desarrollo de competencias en TIC, como parte nodal de la sinergia que debe haber entre los contenidos y las formas didácticas. Todo ello implica un gran esfuerzo por parte de los actores del proceso enseñanza-aprendizaje: académicos, instituciones y educandos; sin embargo, vale la pena, ya que la educación actual requiere formar personas capaces de enfrentar los retos de una sociedad cuya constante es el cambio. De ahí la importancia que tiene haber plantado la semilla del aprendizaje permanente y el compromiso de las personas como seres comprometidos en y con el mundo. Queda como tarea pendiente investigar los resultados de las acciones de los actores del proceso de enseñanza-aprendizaje en entornos virtuales.

Es importante que las instituciones de educación superior se interesen por buscar dar solución a las áreas de oportunidad detectadas en la presente investigación y así captar la percepción tácita de los docentes y discentes, a fin de socializarla y documentarla estratégicamente y hacerla de su propiedad. 


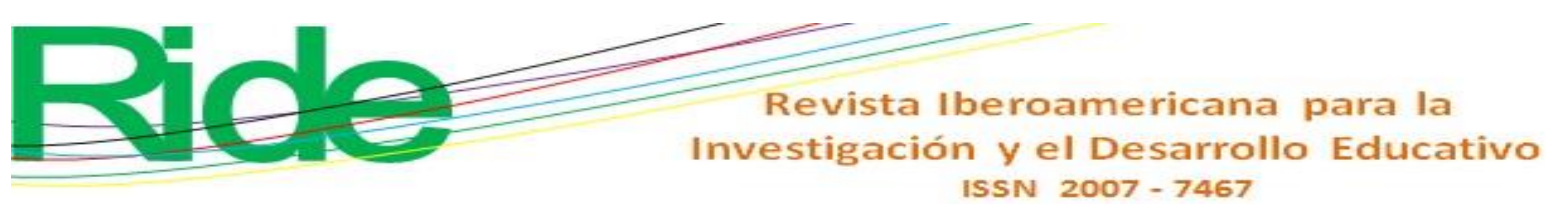

Cruz, F. y Quiñonez, A. (2012). Importancia de la evaluación y autoevaluación en el rendimiento académico. Zona Próxima, (16), 96-104. Recuperado de https://www.redalyc.org/pdf/853/85323935009.pdf.

Falco, M. (2017). Reconsiderando las prácticas educativas: TICs en el proceso de enseñanzaaprendizaje. Tendencias Pedagógicas, 29, 59-76. Recuperado de https://revistas.uam.es/tendenciaspedagogicas/article/view/7084/0.

Frías, D. (2014). Alfa de Cronbach y consistencia interna de los ítems de un instrumento de medida. Recuperado de http://www.uv.es/friasnav/ApuntesSPSS.pdf.

García, A. y Arras, A. M. (2011). Competencias en TIC y rendimiento académico en la universidad, diferencias por género. México: Pearson.

García, R. (2017). El reto de la formación en competencias digitales el proyecto SOLA y su papel en la UDEIMA. Tecnología, Ciencia y Educación, (6), 145-151. Recuperado de http://revistasocitec.org/judima/index.php/TCE/article/view/120/106.

Guzmán, I., Marín, R. e Inciarte, A. D. (2014). Innovar para transformar la docencia universitaria. Un modelo para la formación por competencias. Maracaibo, Venezuela: Universidad de Zulia.

Hernández, N., Muñoz, P. C. y González, M. (2018). La e-evaluación en el trabajo colaborativo en entornos virtuales: análisis de la percepción de los estudiantes. Revista Electrónica de Tecnología Educativa, (65), 16-28. Recuperado de dx.doi.org/10.21556/edutec.2018.65.997.

Hinojosa, M., González, V. P. y Castillo, J. A. (2017). Estudio de competencias genéricas y la calidad en el desempeño de estudiantes mediante análisis multivariado. Revista Electrónica $\begin{array}{llll}\text { ANFEI, } & \text { (6). Recuperado de }\end{array}$ http:/anfei.org.mx/revista/index.php/revista/article/view/349/990.

Hirsch, A. (2005). Construcción de una escala de actitudes sobre ética profesional. Revista Electrónica de Investigación Educativa, 7(1). Recuperado de http://redie.uabc.mx/redie/article/view/125. 


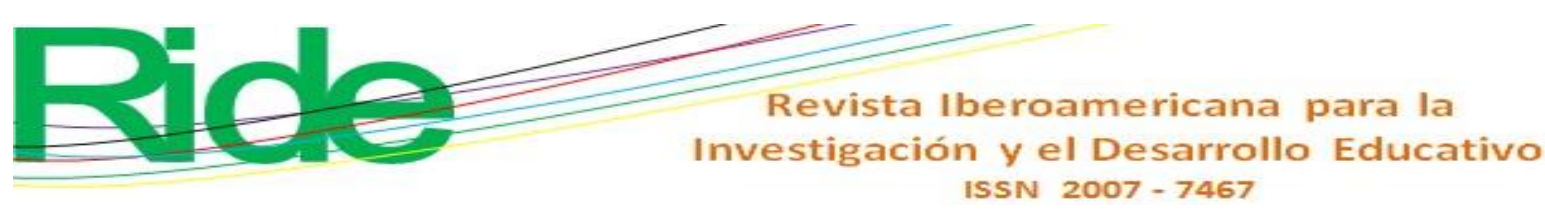

International Business Machines [IBM]. (2016). Software SPSS. Retrieved from https://www01.ibm.com/software/mx/analytics/spss/.

Jaramillo, P., Henning, C. y Rincón, C. (2011). ¿Cómo manejan información los estudiantes de educación superior? El caso de la Universidad de La Sabana, Colombia. Información,

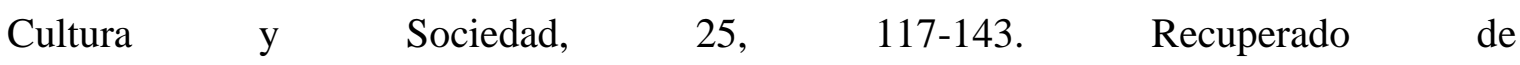
http://www.scielo.org.ar/scielo.php?script=sci_arttext\&pid=S1851-17402011000200007.

Landero, R. y González, M. (2006). Estadística con SPSS y metodología de la investigación. Ciudad de México, México: Trillas.

Ling, R. y Bertel, T. (2013). Mobile Communication culture among children and adolescents and media. New York, United States: Routledge.

Llamas, F. y Macías, E. (2016). Formación inicial de docentes en educación básica para la generación de conocimiento con las Tecnologías de la Información y la Comunicación. Revista Complutense de Educación, 29(2), 577-593. Recuperado de http://dx.doi.org/10.5209/RCED.53520.

López, V. P., González, V., Aguiar, M. V. y Artiles, J. (2017). La gestión de la información en entornos personales de aprendizaje: estudio exploratorio en alumnado de último curso de grado. Revista Complutense de Educación, 28(4), 1303-1320. Recuperado de http://revistas.ucm.es/index.php/RCED/article/view/51849/51789.

Mañas, A. y Roig, R. (2019). Las Tecnologías de la Información y la Comunicación en el ámbito educativo. Un tándem necesario en el contexto de la sociedad actual. Revista Internacional d'Humanitats, $\quad 45, \quad 75-86 . \quad$ Recuperado de https://rua.ua.es/dspace/bitstream/10045/82089/1/2018_Manas_Roig_RevIntHumanitats.p df.

Marcial, D. (2017). ICT Social and Ethical competency among teacher educators in the philippines. Information Technologies and Learning Tools, 57(1), 96-103. Retrieved from http://journal.iitta.gov.ua/index.php/itlt/article/view/1533/1137. 


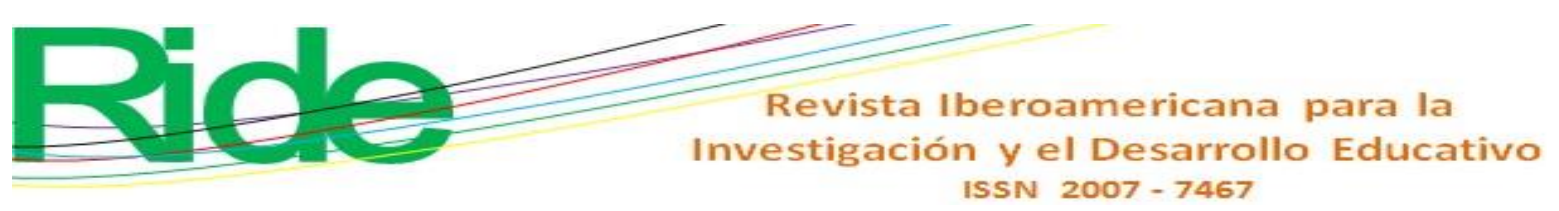

Moreno, M. A., Nelly, E. y García, D. J. (2013). Percepción de los estudiantes de enfermería sobre el ambiente de aprendizaje durante sus prácticas clínicas. Revista CUIDARTE, 4(1), 444459.

Olmos, S. y Rodríguez, M. J. (2010). Diseño del proceso de evaluación de los estudiantes universitarios españoles: ¿responde a una evaluación por competencias en el Espacio Europeo de Educación Superior? Revista Iberoamericana de Educación, 53(1), 1-13.

Organización de las Naciones Unidas para la Educación, Ciencia y la Cultura [Unesco]. (2008). Estándares TIC para la formación inicial docente: Una propuesta en el contexto chileno. Santiago, Chile: Centro de Educación y Tecnología del Ministerio de Educación de Chile / Organización de las Naciones Unidas para la Educación, Ciencia y la Cultura. Recuperado de https://unesdoc.unesco.org/ark:/48223/pf0000163149/PDF/163149spa.pdf.multi.

Paredes, V. (2019). Brecha en el uso de tecnologías de la información y comunicación (TIC) básicas y modernas entre estudiantes y docentes en universidades ecuatorianas. Revista Educación, $\quad 43(1), \quad 2215-2644 . \quad$ Recuperado de https://doi.org/10.15517/revedu.v43i1.27423.

Plaza de la Hoz, J. (2018). Ventajas y desventajas del uso adolescente de las TIC: visión de los estudiantes. Revista Complutense de Educación, 29(2), 491-508. Recuperado de http://revistas.ucm.es/index.php/RCED/article/view/53428/4564456546948.

Prendes, M. P., Solano, I. M., Serrano, J. L., González, V. y Román, M. D. (2018). Entornos Personales de Aprendizaje para la comprensión y desarrollo de la Competencia Digital: análisis de los estudiantes universitarios en España. Educatio Siglo XXI, 36(2), 115-134. Recuperado de https://revistas.um.es/educatio/article/view/333081/231181.

Ramírez, U. y Barragán, J. F. (2018). Autopercepción de estudiantes universitarios sobre el uso de tecnologías digitales para el aprendizaje. Apertura, 10(2), 94-109. Recuperado de http://dx.doi.org/10.18381/Ap.v10n2.1401.

Santos, G. y Tirado, F. (2019). Transformando la educación: análisis de diseños para la construcción de conocimiento por colaboración. Revista de la Educación Superior, 48(189), 21-53. 


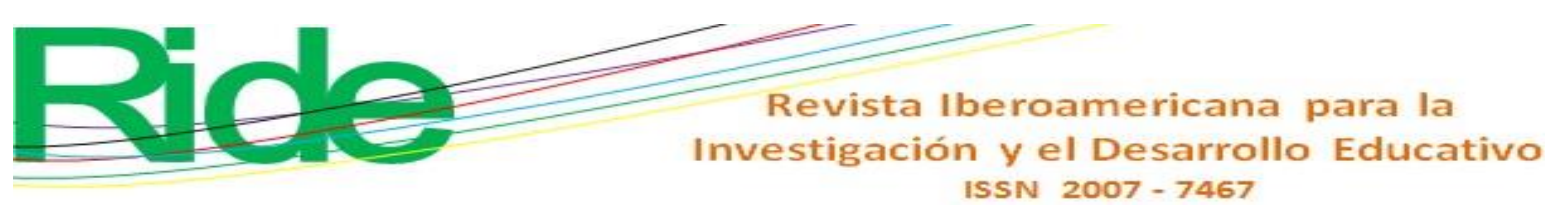

Sing, C. (2010). The relationships among Singaporean preservice teachers' ICT competencies, pedagogical beliefs and their beliefs on the espoused use of ICT. The Asia-Pacific Education Researcher, 19(3), 387-400. Retrieved from https://repository.nie.edu.sg/handle/10497/4791.

Universidad Autónoma de Chihuahua. (2018). Historia. México: Universidad Autónoma de Chihuahua. Recuperado de: https://www.uach.mx/acerca/historia/.

Velarde, O., Bernete, F. y Franco, D. (2015). Paradigmas de los efectos de las TIC en la cultura y en el conocimiento. Revista Latina de Comunicación Social, 70, 347-379.

Villarruel, M. (2015). La investigación y el investigador en la percepción de estudiantes de maestría en educación. Trilogía. Ciencia, Tecnología y Sociedad, 7(12), 39-57.

Yin, R. (2003). Case Study Research: Design and Methods (3rd ed.). United States: Sage Publications. 
